\title{
Association between vitamin D, parathyroid hormone and inflammatory markers in urolithiasis patients
}

\author{
Shakila Venkatesan ${ }^{1}$, Kalyani Chakkarai ${ }^{1}$, Subramaniam Arulvijayavani ${ }^{1,2}$, Gandhipuram Periyasamy \\ Senthilkumar ${ }^{*}$, Ramanitharan Manikandan ${ }^{3}$, Muruganandham Kalyaperumal ${ }^{3,4}$ \\ ${ }^{1}$ Department of Biochemistry, Jawaharlal Institute of Postgraduate Medical Education and Research, Puducherry, India \\ ${ }^{2}$ Department of Biochemistry, Mahatma Gandhi Medical College and Research Institute, Puducherry, India \\ ${ }^{3}$ Department of Urology, Jawaharlal Institute of Postgraduate Medical Education and Research, Puducherry, India \\ ${ }^{4}$ Department of Urology, Global hospital, Chennai, India
}

\section{A R T I C L E I N F O}

Article Type:

Original

\section{Article History:}

Received: 27 January 2017

Accepted: 20 May 2017

Published online: 8 June 2017

Keywords:

Urolithiasis

Vitamin D

Parathyroid hormone

Interleukin-6

Highly sensitive C-reactive protein

\begin{abstract}
A B S T R A C T
Introduction: Hypercalciuria plays an important role in the pathogenesis of renal calculi. The role of vitamin D, parathyroid hormone (PTH), inflammatory markers highly sensitive C-reactive protein (hs-CRP) and interleukin-6 (IL-6) in the development of renal calculi has not well defined.

Objectives: To assess the serum levels of vitamin D, PTH, hs-CRP and IL-6, urinary and serum calcium and phosphorus levels in patients with renal calculi and to compare these parameters with healthy controls

Patients and methods: It was a cross-sectional study. About 41 confirmed renal calculi patients and 41 age and sex matched controls were recruited. Patients with malignancies, hyperparathyroidism, chronic disease, and patients taking vitamin D supplementations were excluded. Serum levels of $25(\mathrm{OH})$ vitamin D, i-PTH, hs-CRP, IL-6, calcium and phosphorous, 24 hours urine levels of calcium and phosphorus were estimated

Results: There was a statistical significant difference in the serum levels of $25(\mathrm{OH})$ vitamin D (12.26 vs $19.61 \mathrm{ng} / \mathrm{mL})$, i-PTH (75.5 vs. $33.5 \mathrm{pg} / \mathrm{mL}$ ), hsCRP (5117.05 vs. $1721.87 \mathrm{ng} / \mathrm{mL}$ ), IL-6 (13.49 vs. $1.47 \mathrm{pg} / \mathrm{mL})$ calcium (11.5 vs. $9.4 \mathrm{mg} / \mathrm{dL})$ and urinary calcium (370.5 vs. 342 $\mathrm{mg} / \mathrm{d}$ ) and phosphorous levels (1172 vs. $1432 \mathrm{mg} / \mathrm{d}$ ) between the cases and the control. There was negative correlation between the levels of i-PTH and vitamin $\mathrm{D}(r=-0.765)$ and positive correlation between i-PTH and hsCRP, IL-6, Serum calcium and urine calcium $(r=0.353$, $0.340,0.522,0.501$ respectively)

Conclusion: There was vitamin D inadequacy and increased levels of PTH, IL- 6 and C-reactive protein, calcium in patients with renal calculi when compared with healthy controls.
\end{abstract}

Implication for health policy/practice/research/medical education:

As urolithiasis patients are at a constant inflammatory insult caused by the calculi, the levels of inflammatory markers can be used to monitor the success of treatment. Vitamin D and anti-inflammatory agents may be used in the management of nephrolithiasis patients.

Please cite this paper as: Venkatesan S, Chakkarai K, Arulvijayavani S, Senthilkumar GP, Manikandan R, Kalyaperumal M. Association between vitamin D, parathyroid hormone and inflammatory markers in urolithiasis patients. J Renal Inj Prev. 2017;6(4):240-243. DOI: 10.15171/jrip.2017.45.

\section{Introduction}

Renal calculi are a global health problem afflicting human beings for several centuries. The prevalence of nephrolithiasis in men is approximately 6\%-9\% and in women, it is almost 3\%-4\% (1). The most common type of renal stone is calcium oxalate followed by mixed calcium oxalate and phosphate, struvite, uric acid, calcium phosphate and cystine stones (2).

Hypercalciuria is considered as an important etiological factor involved in the formation of calcium related renal calculi (3). Vitamin D acts as a hormone to maintain plasma calcium homeostasis by acting in mainly three organs like kidney, small intestine and bone (4).

Previous studies had showed that nutritional vitamin D 
inadequacy (VDI) and deficiency are present worldwide $(5,6)$. Approximately 1 billion individuals were found to be have low levels of vitamin D (7). The patients having VDI may develop secondary hyperparathyroidism (HPT) (8). It may underlie hypercalciuria in stone formers. The risk of renal calculi increases with hyperparathyroidism (9).

Interleukin-6 (IL-6), produced by lymphocytes, monocytes, is a potent anti-inflammatory cytokine mediating the inflammatory process. Recently it was proved that hyperparathyroidism causes a significant increase in IL-6 levels (10). C-reactive protein (CRP) is an acutephase protein. Its blood level increases in the presence of inflammation or tissue injury.

To date, the prevalence of VDI in patients with renal calculi is not known, and there are no data characterizing the metabolic abnormalities in these patients presenting with stone disease. The associations of parathyroid hormone (PTH), CRP and IL-6 with renal calculi have not been reported till this date. Hence, we indented to study the concentrations of vitamin D, PTH, CRP, IL-6, urinary and serum calcium and phosphorus levels in patients with renal calculi and to compare these parameters with healthy controls.

\section{Patients and Methods}

Study design

This was a cross-sectional study conducted in Jawaharlal Institute of Postgraduate Medical Education and Research (JIPMER), Puducherry, India by the Department of Biochemistry, in collaboration with Department of Urology, JIPMER, from a period of one year (2013-2014). A total of 82 subjects were enrolled in the study and were divided into two groups.

Group A includes patients with renal calculi (18-50 years) confirmed by plain kidney, ureter and blabber (KUB) X-ray and/or ultrasound $\mathrm{KUB} /$ computerized tomography (CT) scan of kidney $(\mathrm{n}=41)$.

Group B includes age and sex matched healthy subjects ( $\mathrm{n}$ $=41$ ).

Patients with a history of known malignancies, hypertension, diabetes, infection, inflammatory disorders, cardiac disease, obstructive uropathy/ureteric colic, hyperparathyroidism, renal failure, metabolic bone diseases, any other urogenital disorders, and patients taking vitamin D supplementations were excluded. Data were recorded in a pre-designed proforma. Clinical parameters of the study subjects were recorded. Serum 25 -hydroxy vitamin D level $<20 \mathrm{ng} / \mathrm{mL}$ was considered as a deficient range and levels between $20-$ $30 \mathrm{ng} / \mathrm{mL}$ were considered as insufficient range and levels $>30 \mathrm{ng} / \mathrm{mL}$ was considered as the normal range of vitamin $\mathrm{D}(7)$.

\section{Sample collection}

Five milliliters of venous blood sample was collected from both the cases and controls after getting written informed consent. Sample was centrifuged at $5000 \mathrm{rpm}$ for 10 minutes at room temperature, and serum separated was used to analyze calcium and phosphate immediately. Remaining serum sample was stored at -80 degree Celsius for analyzes of parameters like 25(OH) vitamin D, iPTH (intact PTH), hs-CRP (highly sensitive CRP) and IL-6. Twenty-four hours urine sample was collected from all the study subjects after giving proper instructions. Additionally, 24 hours urine levels of calcium and phosphorus were estimated immediately.

Serum and urine calcium levels were assayed using modified Arsenazo III method using reagent kit from Agappe Diagnostics, Kerala (11). Serum and urinary levels of phosphorus were measured using phosphomolybdate method (Genuine Biosystem, India) (12). Serum 25 $(\mathrm{OH})$ vitamin D level was estimated using commercially available enzyme-linked immunosorbent assay (ELISA) kits (MicroVue 25-OH Vitamin D Enzyme immunoassay Quidel Corporation, USA) (13). Serum hs-CRP levels and IL-6 were assayed by means of ELISA kits - Diagnostics Biochem Canada Inc, Ontario, Canada and Diaclone SAS, France respectively $(14,15)$. PTH was estimated by two-site sandwich immunoassay using direct chemiluminometric technology (ADVIA Centaur Siemens) (16).

\section{Ethical issues}

The research followed the tenets of the Declaration of Helsinki; informed consent was obtained. This study was approved by the JIPMER research committee and Institute Ethics Committee (Human studies) with grant No. JIR/ IEC/SC/2013/5/437.

\section{Statistical analysis}

Distribution of the data was checked. The results were expressed as mean \pm standard deviation or median with range, and biochemical parameters were compared between the study groups using unpaired students $t$ test or Mann-Whitney U-test accordingly. The correlations between parameters were tested by Spearman's correlation. All statistical analysis was carried out at 5\% level of significance for two-tailed significance using SPSS version 19.0 for Windows.

\section{Results}

The level of serum 25(OH) vitamin D was deficient in both cases and controls. Though there was a decrease in the concentration of serum $25(\mathrm{OH})$ vitamin $\mathrm{D}$ in both cases and controls, there was statistically significant difference between them. There was secondary hyperparathyroidism in patients with renal calculi. The levels of iPTH (75.5 vs. $33.5 \mathrm{pg} / \mathrm{mL}$ ), hsCRP (5117.05 vs. $1721.87 \mathrm{ng} / \mathrm{mL}$ ), IL-6 (13.49 vs. $1.47 \mathrm{pg} / \mathrm{mL}$ ) were significantly high in cases compared to controls. There was statistically significant difference in the levels of serum calcium, urinary calcium and phosphorous between cases and control but there was no significant difference in the level of serum phosphorus (Table 1).

There was negative correlation between the levels of iPTH and vitamin $\mathrm{D}(r=-0.765)$ and there was positive correlation between the levels of iPTH and hsCRP $(r=0.353)$, IL-6 $(r=0.340)$, serum calcium $(r=0.522)$ and urine calcium $(r=0.501)$. There was no correlation between iPTH and phosphorous levels in both serum and urine (Table 2). 
Table 1. Comparison of parameters between control and renal calculi groups

\begin{tabular}{|c|c|c|c|}
\hline Parameter & $\begin{array}{c}\text { Control } \\
n=41\end{array}$ & $\begin{array}{l}\text { Cases } \\
\mathbf{n}=41\end{array}$ & $P$ value \\
\hline Serum $250 \mathrm{OH}$ vitamin $\mathrm{D}(\mathrm{ng} / \mathrm{mL})$ & $19.61(14.14-43.30)$ & $12.26(9.67-15.89)$ & $0.000^{b}$ \\
\hline Parathyroid hormone (pg/mL) & 33.5 (19.6-61.4) & $75.5(56.85-97.25)$ & $0.000^{b}$ \\
\hline C-reactive protein $(\mathrm{ng} / \mathrm{mL})$ & $1721.87(560.53-6304.82)$ & 5117.05 (1279.26-10500) & $0.002^{b}$ \\
\hline Interleukin $-6(\mathrm{pg} / \mathrm{mL})$ & $1.47(0-6.97)$ & $13.49(3.13-35.46)$ & $0.000^{b}$ \\
\hline Serum calcium (mg/dL) & $9.4(9.2-9.8)$ & $11.5(11.0-11.8)$ & $0.000^{\mathrm{b}}$ \\
\hline Urinary calcium (mg/day) & 342 (220.5-391.9) & $370.5(343.5-420.25)$ & $0.005^{b}$ \\
\hline Serum phosphorous $(\mathrm{mg} / \mathrm{dL})^{\mathrm{a}}$ & $3.98 \pm 0.47$ & $3.98 \pm 0.44$ & 0.75 \\
\hline Urinary phosphorous (mg/day) & 1432 (1361.5-1498) & $1172.0(673-1315)$ & $0.000^{b}$ \\
\hline
\end{tabular}

Data expressed as median and range. $P<0.05$ was considered as significant.

${ }^{\text {aD }}$ Data expressed as mean \pm standard deviation.

${ }^{\text {b }}$ Statistically significant.

Table 2. Correlation between parathyroid hormone and hs-CRP, IL-6, Serum $25(\mathrm{OH})$ vitamin D, serum calcium and urine calcium levels

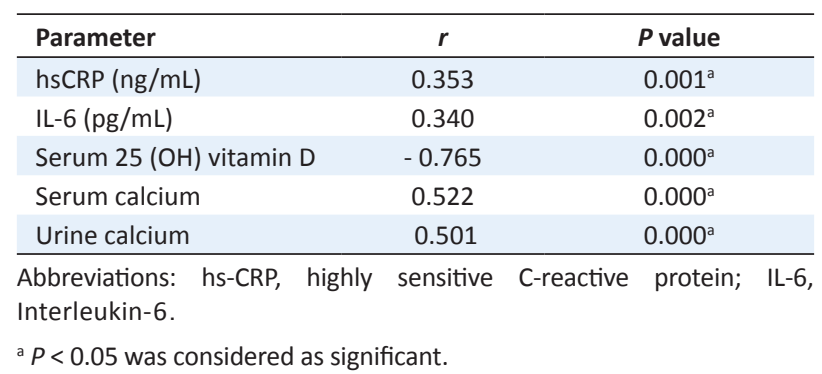

\section{Discussion}

Vitamin $\mathrm{D}$ is a fat-soluble vitamin known for its pleiotropic actions. It plays a key role in the regulation of calcium hemostasis both in normal patients and in urolithiasis patients. It also plays an important role in the pathogenesis of kidney stone formation (17). Vitamin D insufficiency and deficiency is common in kidney stone patients. Urinary abnormalities frequently observed in patients with VDI are suboptimal volume, hypocitraturia, hypocalciuria, hypercalciuria, hyperuricosuria, cystinuria, and hyperoxaluria (18).

VDI leads to hypocalcemia which in turns leads to increased parathyroid hormone production. This condition is termed as secondary hyperparathyroidism. Augmented serum levels of parathyroid hormone increase intestinal absorption, bone resorption, and renal reabsorption of calcium leading to hypercalcemia. In spite of increased renal reabsorption of calcium, hypercalciuria is produced from the excess calcium load. Thus, one may find hypercalciuria in all patients with untreated HPT, and place all patients at an increased risk of renal calculi $(19,20)$. In the present study, there was a positive correlation between PTH levels and urinary calcium level which is in agreement with the previous studies (21).

Nephrolithiasis is considered as a state of chronic inflammation (22). Increased PTH levels are associated with low-grade inflammation, and it stimulates the releases of cytokine IL-6 from liver and osteoblasts. IL-6, in turn, may modulate the production of acute phase proteins like CRP in liver (10). There was increased $\mathrm{m}$-RNA expression of IL-6 in nephrolithiasis (23). The levels of IL-6 were increased in patients with renal calculi than in healthy controls. It is still unclear that whether, IL-6 was released due to irritation of the epithelial cells by renal calculi or it was the cause for the renal stones (1).

IL-6 increases the production of CRP from liver which is a non-specific indicator of inflammation at a low grade. Previous studies have shown an association between CRP levels and nephrolithiasis (24). It has been used as a marker in acute inflammation and urinary tract obstruction in renal colic patients and to decide the placement of urinary stent (25). Serum iPTH level is used as a predictor of chronic inflammation and dyslipidemia in obese individuals, independent of $25(\mathrm{OH})$ vitamin $\mathrm{D}(26)$. In the present study, there was an increase in the levels of inflammatory markers IL-6, hsCRP in renal calculi patients and a positive correlation was found between PTH levels and IL-6 and hsCRP levels. This report is similar to the study done by Tsao et al, who concluded that acute inflammation markers, adhesion molecules were increased in patients with renal calculi (27). These results suggest that patients with urolithiasis are at a constant inflammatory insult caused by the calculi. These markers can be used to indicate the presence of calculi and to monitor the success of stone removal. Further studies are needed to establish the role of vitamin $\mathrm{D}$ supplementation and anti-inflammatory agents in the management of nephrolithiasis patients.

\section{Conclusion}

The present study concludes that there was VDI and increased levels of parathyroid hormone, IL-6, C-reactive protein and calcium in patients with renal calculi compared with healthy controls.

\section{Limitations of the study}

The limitations of the present study were smaller sample size and lack of dietary history regarding consumption of foods rich in vitamin D. Also, the levels of ionized calcium were not measured.

\section{Acknowledgments}

Authors would like to thank the JIPMER management for supporting this work.

Authors' contribution

SV and KC were involved in sample collection. SA processed 
the samples and did statistical analysis. GPS was involved in protocol design, and methodology. MR and MK helped in recruiting the patients, and protocol development.

\section{Conflicts of interest}

The authors declare no conflict of interest.

\section{Ethical considerations}

Ethical issues (including plagiarism, data fabrication, double publication) have been completely observed by authors.

\section{Funding/Support}

This project is financially supported and beholden by a grant from JIPMER (Grant No- JIP/Res/Intra-Msc/01/2014 dated 13/02/2014) and was extracted from Shakila Venkatesan and Kalyani Chakkarai Master of science thesis.

\section{References}

1. Hasna A, Meiyappan K, Periyasam SG, Kalyaperumal M, Bobby Z, Subramaniam AVV. Is urolithiasis associated with increased levels of high sensitivity $\mathrm{C}$-reactive protein and interleukin-6 in diabetic patients? J Clin Diagn Res. 2015;9:BC01-3. doi: 10.7860/JCDR/2015/12489.5681.

2. Eisner BH, Eisenberg ML, Stoller ML. Relationship between body mass index and quantitative 24-hour urine chemistries in patients with nephrolithiasis. Urology. 2010;75:1289-93. doi: 10.1016/j.urology.2009.09.024.

3. Parmar MS. Kidney stones. BMJ. 2004;328:1420-4. doi: 10.1136/bmj.328.7453.1420.

4. Moe SM. Disorders involving calcium, phosphorus, and magnesium. Prim Care. 2008;35:215-vi. doi: 10.1016/j. pop.2008.01.007.

5. Mithal A, Wahl DA, Bonjour JP, Burckhardt P, DawsonHughes B, Eisman JA, et al. Global vitamin D status and determinants of hypovitaminosis D. Osteoporos Int. 2009;20:1807-20. doi: 10.1007/s00198-009-0954-6.

6. Adams JS, Hewison M. Update in vitamin D. J Clin Endocrinol Metab. 2010;95:471-8. doi: 10.1210/jc.20091773.

7. Holick MF. Vitamin D deficiency. N Engl J Med. 2007;357:26681. doi: 10.1056/NEJMra070553.

8. Lips P. Vitamin D deficiency and secondary hyperparathyroidism in the elderly: consequences for bone loss and fractures and therapeutic implications. Endocr Rev. 2001;22:477-501. doi: 10.1210/edrv.22.4.0437.

9. Craven BL, Passman C, Assimos DG. Hypercalcemic states associated with nephrolithiasis. Rev Urol. 2008;10:218-26.

10. Cheng SP, Liu CL, Liu TP, Hsu YC, Lee JJ. Association between parathyroid hormone levels and inflammatory markers among US Adults. Mediators Inflamm. 2014;2014:e709024. doi: $10.1155 / 2014 / 709024$.

11. Bauer PJ. Affinity and stoichiometry of calcium binding by arsenazo III. Anal Biochem. 1981;110:61-72.

12. Daly JA, Ertingshausen G. Direct method for determining inorganic phosphate in serum with the "CentrifiChem." Clin Chem. 1972;18:263-5.
13. Holick MF. Vitamin D status: measurement, interpretation, and clinical application. Ann Epidemiol. 2009;19:73-8. doi: 10.1016/j.annepidem.2007.12.001.

14. Wilkins J, Gallimore JR, Moore EG, Pepys MB. Rapid automated high sensitivity enzyme immunoassay of C-reactive protein. Clin Chem. 1998;44:1358-61.

15. Wojciechowska-Lacka A, Adamiak E, Stryczynska G, Lacki JK. Prognostic value of serial serum interleukin-6 level estimation in patients with lung cancer: a preliminary report. Yale J Biol Med. 1997;70:139-48.

16. Lepage R, Roy L, Brossard JH, Rousseau L, Dorais C, Lazure C, et al. A non-(1-84) circulating parathyroid hormone (PTH) fragment interferes significantly with intact PTH commercial assay measurements in uremic samples. Clin Chem. 1998;44:805-9.

17. Tang J, Chonchol MB. Vitamin D and kidney stone disease. Curr Opin Nephrol Hypertens. 2013;22:383-9. doi: 10.1097/ MNH.0b013e328360bbcd.

18. Elkoushy MA, Sabbagh R, Unikowsky B, Andonian S. Prevalence and metabolic abnormalities of vitamin D-inadequate patients presenting with urolithiasis to a tertiary stone clinic. Urology. 2012;79:781-5. doi: 10.1016/j. urology.2011.09.004.

19. Rejnmark L, Vestergaard P, Mosekilde L. Nephrolithiasis and renal calcifications in primary hyperparathyroidism. J Clin Endocrinol Metab. 2011;96:2377-85. doi: 10.1210/jc.20110569.

20. Vestergaard P. Primary hyperparathyroidism and nephrolithiasis. Ann Endocrinol. 2015;76:116-9.

21. Sorensen MD, Duh QY, Grogan RH, Tran TC, Stoller ML. Urinary parameters as predictors of primary hyperparathyroidism in patients with nephrolithiasis. J Urol. 2012;187:516-21. doi: 10.1016/j.juro.2011.10.027.

22. Khan SR. Reactive oxygen species, inflammation and calcium oxalate nephrolithiasis. Transl Androl Urol. 2014;3:256-76. doi: 10.3978/j.issn.2223-4683.2014.06.04.

23. Boonla C, Hunapathed C, Bovornpadungkitti S, Poonpirome $\mathrm{K}$, Tungsanga K, Sampatanukul P, et al. Messenger RNA expression of monocyte chemoattractant protein-1 and interleukin-6 in stone-containing kidneys. BJU Int. 2008;101:1170-7. doi: 10.1111/j.1464-410X.2008.07461.

24. Shoag J, Eisner BH. Relationship between C-reactive protein and kidney stone prevalence. J Urol. 2014;191:372-5. doi: 10.1016/j.juro.2013.09.033.

25. Angulo JC, Gaspar MJ, Rodríguez N, García-Tello A, Torres $\mathrm{G}$, Nunez $\mathrm{C}$. The value of $\mathrm{C}$-reactive protein determination in patients with renal colic to decide urgent urinary diversion. Urology. 2010;76:301-6.

26. Alemzadeh R, Kichler J. Parathyroid hormone is associated with biomarkers of insulin resistance and inflammation, independent of vitamin D status, in obese adolescents. Metab Syndr Relat Disord. 2012;10:422-9. doi: 10.1089/ met.2012.0056.

27. Tsao KC, Wu TL, Chang PY, Sun CF, Wu LL, Wu JT. Multiple risk markers for atherogenesis associated with chronic inflammation are detectable in patients with renal stones. J Clin Lab Anal. 2007;21:426-31. doi: 10.1002/jcla.20215.

Copyright (c) 2017 The Author(s); Published by Nickan Research Institute. This is an open-access article distributed under the terms of the Creative Commons Attribution License (http://creativecommons.org/licenses/by/4.0), which permits unrestricted use, distribution, and reproduction in any medium, provided the original work is properly cited. 